\title{
Integrated Control of Hydromechanical Variable Transmissions
}

\author{
Shujun Yang, Yong Bao, Xianzhi Tang, Xiaojuan Jiao, Deqing Yang, and Qing Wang \\ College of Vehicles and Energy, Yanshan University, 438 Hebei Avenue, Qinhuangdao 066004, China \\ Correspondence should be addressed to Shujun Yang; ysj@ysu.edu.cn
}

Received 22 January 2015; Revised 11 June 2015; Accepted 26 July 2015

Academic Editor: Jason Gu

Copyright (C) 2015 Shujun Yang et al. This is an open access article distributed under the Creative Commons Attribution License, which permits unrestricted use, distribution, and reproduction in any medium, provided the original work is properly cited.

\begin{abstract}
A hydromechanical variable transmission (HMT) has advantages of continuous variation and high efficiency. So it is one of the ideal transmissions of heavy vehicles. The continuous speed varying process involves speed governing in range and range shift. Integrated control strategy of the HMT is proposed in this paper. The algorithm of the asymmetric saturated incremental proportional integral derivative (PID) speed control strategy in range and range shift conditions are derived. And this paper presents the range shift logic and range shift control strategies. A controller model is built in Matlab Simulink and cosimulated with the model of vehicle equipped with a two-range HMT. The HMT prototype hardware-in-the-loop simulation (HILS) platform of the integrated control strategy is built. The HILS results show that the range shift process is smooth and speed fluctuation does not happen. In the throttle stable stage, the engine speed is adjusted to the near optimal speed, and its change rules are in accordance with simulation results. The integrated control strategy is reasonable.
\end{abstract}

\section{Introduction}

With the development of automotive industry, customers enhance the requirements of comfort and fuel-efficiency. Transmissions are important to satisfy the requirements $[1,2]$.

The fundamentals and speed ratio characteristics of HMT are shown in Figure 1. Input power is divided into two parts: hydraulic power and mechanical power in the power-split unit $\mathrm{S}$. The hydraulic transmission $\mathrm{H}$ involves a variable displacement hydraulic pump and a fixed displacement motor. By changing the displacement of pump, the motor speed is controlled to vary continuously between the minimum (negative) and maximum (positive) speed, which is defined as a stroke. Each stroke is matched up with a working mode of the mechanical transmission $\mathrm{M}$, which is defined as a range. Finally, two power flows converge into a continuously variable power flow in the conflux unit $\mathrm{C}$.

HMT is a new continuously variable transmission. It makes engine work in high efficient area, so it has the advantage of high efficiency. And it could transmit larger load than the belt type of continuously variable transmission (CVT). Hence, HMT is one of ideal transmissions for heavy trucks [3]. And it has been successfully applied to heavy vehicles [4-6].
Based on lots of research effort on design and simulation of HMT, a series of methods for design and analysis have been established. Linares et al. [5] explained the basics of all types of CVT transmission and described the design parameters and fundamentals of a power-split system. Macor and Rossetti [7] optimized the design of a HMT and got a good speed convergence and a high average efficiency. To develop the control system of a HMT, Zhang and Zhuo [8] built a model of HMT using the principle of dynamics. Choi et al. [9] conducted a simulator for a tractor with HMT, under working and driving modes. And the tractor speed and the engine speed could be maintained at the desired values. Compared with the technologies of HMT design and analysis, control of HMT is still at an early developing stage.

The speed varying process consists of speed governing in range and range shift. Therefore, the speed governing in range, timing of range shift, and methods of shift are all necessary. Lots of studies were about speed governing in range and control components. Yuan et al. [10] and Wei et al. [11] designed a variable parameter PID controller and studied a speed control system on HMT. In their researches, target speed ratio follow-up could be realized. But their researches focused only on speed ratio control in range. Hu et al. [12] 


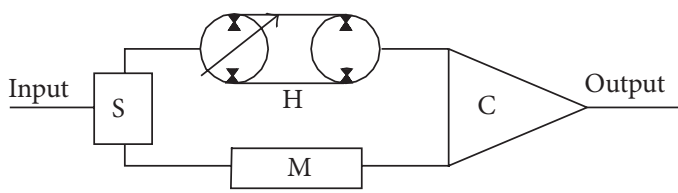

S: Power-split unit H: Hydraulic transmission C: Conflux unit M: Mechanical transmission

(a) Fundamentals of HMT

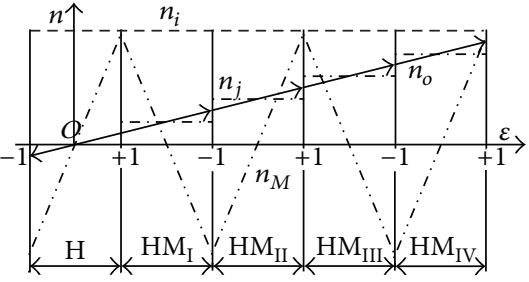

$n_{i}$ : Input speed $\quad n_{j}$ : Mechanical transmission speed $n_{o}$ : Output speed $\quad n_{M}$ : Motor speed

(b) Speed ratio characteristics

FIgURE 1: Fundamentals and speed ratio characteristics of HMT.

explored the feasibility of shift without power interruption. Zhang and Zhuo [13] presented a speed variation and range shift method to achieve the widest speed range and avoid repeating shift. Savaresi et al. [14] designed a control system, including a servocontroller on valve, a servocontroller on hydraulic speed ratio, and a synchronizer. But improvements in tractor's performance were obtained only by replacing the current pump/motor and speed detectors. Tanelli et al. [15] designed a control system for a tractor equipped with HMT, involving the control of one clutch and two clutch range shifts, and improved shift quality. An integrated control method of HMT is presented in the paper. A controller model is built in Matlab Simulink and cosimulated with the model of vehicle equipped with HMT. The HILS test of HMT is carried out.

\section{The Integrated Control Strategy of HMT}

A two-range HMT is shown in Figure 2 and cited to illustrate the control method. The two-range HMT includes three planetary gear sets $\left(K_{1}, K_{2}\right.$, and $\left.K_{3}\right)$, two brakes $\left(\mathrm{C}_{\mathrm{H}}, \mathrm{C}_{\mathrm{HM}}\right)$, one variable displacement pump $(\mathrm{P})$, and one fixed displacement motor (M). In Figure 2, $n_{i}$ is the input speed of the HMT, and $n_{o}$ is output speed of the HMT. When the brake $\mathrm{C}_{\mathrm{H}}$ is engaged and the brake $\mathrm{C}_{\mathrm{HM}}$ is released, the planetary gear set $K_{1}$ works and the HMT works in hydraulic range $(\mathrm{H})$. When the brake $C_{\mathrm{HM}}$ is engaged and the brake $\mathrm{C}_{\mathrm{H}}$ is released, the planetary gear sets $K_{2}$ and $K_{3}$ work, and the HMT works in hydromechanical range (HM).

The speed characteristics of HMT are made up of several associated infinitely variable ranges. Therefore, the integrated control strategy should involve speed control in range, range shift logic, range shift conditions, and shift control strategies.

HMT speed is governed on the basis of vehicle speed and throttle opening. HMT makes engine and vehicle work in various ways in accordance with the selected mode, to achieve the expected performance.

\section{Speed Control Strategy in Range}

Speed control strategy in range changes the control current of hydraulic pump in accordance with the difference between the engine speed and ideal speed. Speed control strategy in

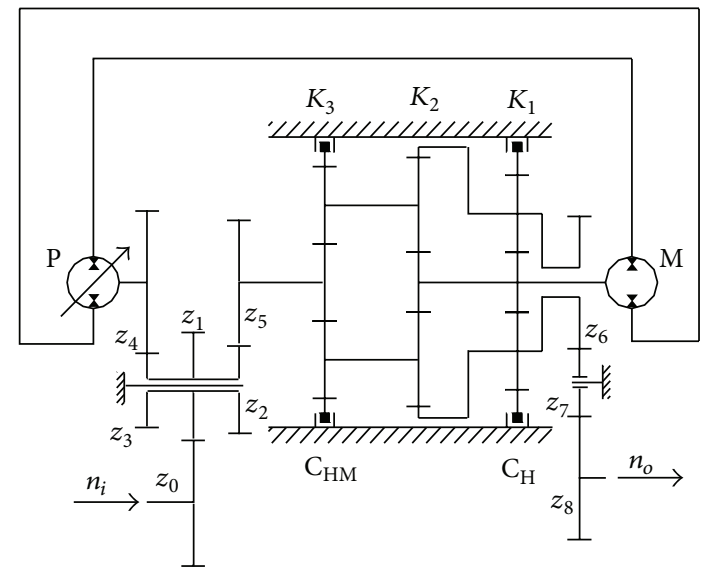

Figure 2: A two-range HMT.

range has been studied for many years, mainly in PID control and the speed ratio tracking control, and so forth [10-13].

In certain road conditions, acceleration of the vehicle with HMT is limited by the engine torque and the maximum motor torque. The maximum motor torque is determined by the maximum pressure on the condition that the motor is selected.

When the error between engine actual speed $n_{e k}$ and target speed $n_{e k}^{*}$ is greater during vehicle acceleration, the gradient of control current variety of the variable displacement pump $\Delta I_{p}(k)$ increases according to PID algorithm. And the gradient of rotational speed variety of motor and vehicle acceleration resistance increase, which make hydraulic unit lose its ability to accelerate the vehicle after the pressure rises up to the maximum pressure. Therefore, when the vehicle accelerates, the upper saturation limit of $\Delta I_{p}(k)$ must be set. When the vehicle decelerates rapidly, the speed ratio of HMT must be able to decrease quickly. So the lower saturation limit of $\Delta I_{p}(k)$ in vehicle deceleration must be greater than that in vehicle acceleration. That is to say, the saturation limits of $\Delta I_{p}(k)$ are asymmetric. In this paper, the asymmetric saturation incremental PID speed control strategy of HMT in range is proposed, and general algorithms in each range are derived. 
3.1. Universal Incremental PID Algorithm. HMT controller refers to a digital PID control unit, and its increment is

$$
\Delta u_{k}=k_{0} e_{k}+k_{1} e_{k-1}+k_{2} e_{k-2}
$$

where $\Delta u_{k}$ means the increment at $t=k T$ and $e_{i}$ means the error at $t=k T_{i}(i=k-2, k-1, k) ; k_{0}, k_{1}$, and $k_{2}$ are coefficients, respectively, where $k_{0}=k_{p}+k_{I}+k_{D}, k_{1}=$ $-\left(k_{p}+2 k_{D}\right), k_{2}=k_{D} ; k_{p}$ refers to a scale factor, and $k_{I}$ refers to an integral factor, $k_{I}=k_{p}\left(T / T_{I}\right) ; k_{D}$ refers to a derivative factor, $k_{D}=k_{p}\left(T_{D} / T\right) ; T_{D}$ means the derivative time constant, $T_{I}$ means the integral time constant, and $T$ means the sampling period.
The output is

$$
u_{k}=u_{k-1}+\Delta u_{k}=u_{k-1}+k_{0} e_{k}+k_{1} e_{k-1}+k_{2} e_{k-2},
$$

where $u_{k-1}$ is the sum of $\Delta u_{i}(i=0 \sim k-1)$.

3.2. The Asymmetric Saturation Incremental PID Speed Control Strategy in Range. The error $e_{k}$ of HMT controller is

$$
e_{k}=n_{e k}-n_{e k}^{*}
$$

where $n_{e k}$ and $n_{e k}^{*}$ are the engine speed and the ideal speed at $t=k T$, respectively.

Equation (2) could be expressed as follows, if $u_{k}$ and $\Delta u_{k}$ are substituted by the pump current $I_{p k}$ and the increment $\Delta I_{p k}$ :

$$
\begin{aligned}
& I_{p k}= \begin{cases}I_{p \max } & I_{p(k-1)} \pm \Delta I_{p k}>I_{p \max } \\
I_{p(k-1)} \pm \Delta I_{p k} & I_{p \min } \leq I_{p(k-1)} \pm \Delta I_{p k} \leq I_{p \max } \\
I_{p \min } & 0 \leq I_{p(k-1)} \pm \Delta I_{p k}<I_{p \min } \\
-I_{p \min } & -I_{p \min } \leq I_{p(k-1)} \pm \Delta I_{p k}<0 \\
I_{p(k-1)} \pm \Delta I_{p k} & -I_{p \max } \leq I_{p(k-1)} \pm \Delta I_{p k}<-I_{p \min } \\
-I_{p \max } & I_{p(k-1)} \pm \Delta I_{p k}<-I_{p \max }\end{cases} \\
& \Delta I_{p k}= \begin{cases}\Delta I_{p \max } & k_{0} e_{k}+k_{1} e_{k-1}+k_{2} e_{k-2}>\Delta I_{p \max } \\
k_{0} e_{k}+k_{1} e_{k-1}+k_{2} e_{k-2} & \Delta I_{p \min } \leq k_{0} e_{k}+k_{1} e_{k-1}+k_{2} e_{k-2} \leq \Delta I_{p \max } \\
\Delta I_{p \min } & k_{0} e_{k}+k_{1} e_{k-1}+k_{2} e_{k-2}<\Delta I_{p \min },\end{cases}
\end{aligned}
$$

where " \pm " is determined by HMT operating ranges. In direct proportion ranges, if gear ratio $i \geq 0$, plus sign is taken; if not, minus sign is taken. In inverse proportion ranges, if gear ratio $i \geq 0$, minus sign is taken; if not, plus sign is taken. In the two-range HMT, $\mathrm{H}$ range is a direct proportion range. In its positive half range, $i \geq 0$, the first " \pm " in (4) takes plus sign. And in the negative half range, $i<0$, the second one takes minus sign. The HM range is an inverse proportion range. Similarly, the first “ \pm ” in (4) takes minus sign, and the second one takes plus sign. $I_{p(k-1)}$ refers to the pump current at $t=(k-1) T . I_{p \max }$ and $I_{p \min }$ are the upper and lower limits of the pump current. In the two-range HMT, the variable displacement hydraulic pump is a Sauer Danfoss Series 90 axial piston pump, where $I_{p \max }=650 \pm 140 \mathrm{~mA}$ and $I_{p \min }=$ $112 \pm 40 \mathrm{~mA}\left(I_{p \min }\right.$ is designed for eliminating zero dead zone of the displacement control mechanism). $\Delta I_{p \max }$ and $\Delta I_{p \min }$ are the asymmetric saturated upper and lower limits of control current gradient, which depend on the displacement of pump/motor, speed ratio, vehicle resistance, and so forth.

In Figure 2, HMT output speed is a function of motor speed. And suitable PID parameters $k_{0}, k_{1}$, and $k_{2}$ in (5) for each range must be selected by a large number of simulations and experiments to reduce the speed fluctuation of motor. Through theoretical calculations and simulations, parameters of the PID controller are as follows: $k_{0 \mathrm{H}}=0.008, k_{1 \mathrm{H}}=$ $-0.009, k_{2 \mathrm{H}}=0.004$ in $\mathrm{H}$ range, $k_{0 \mathrm{HM}}=0.010, k_{1 \mathrm{HM}}=$ $-0.009, k_{2 \mathrm{HM}}=0.004$ in $\mathrm{HM}$ range, $\Delta I_{p \max }=2.4 \mathrm{~mA}$, and $\Delta I_{p \min }=-16 \mathrm{~mA}$.

\section{Range Shift Logic}

Range shift logic is the order of ranges. To realize continuously variable transmission, the HMT range switching elements such as the brakes must be sequentially controlled, and HMT can work in sequential range. The range shift logic of the two-range HMT is shown in Table 1.

\section{Range Shift Conditions}

The range shift refers to a transition process between two adjoining ranges. To improve shift quality, the shift conditions are as follows:

(1) The eventual output speed of HMT in current range should equal that of target range original point. In each range, closed-loop control is applied to control 
TABLE 1: The range shift logic.

\begin{tabular}{lcc}
\hline Range & \multicolumn{2}{c}{ Brake } \\
& $C_{\mathrm{H}}$ & $C_{\mathrm{HM}}$ \\
\hline H range & Engagement & Disengagement \\
HM range & Disengagement & Engagement \\
\hline
\end{tabular}

the motor speed. The ideal shift time is obtained in accordance with engine speed and motor speed.

The target motor speed $n_{m}^{*}$ occurs at the ideal shift point where the speeds of driving and driven discs of the target brake are equal. In the two-range HMT, the ideal speed $n_{m}^{*}$ from $\mathrm{H}$ range to $\mathrm{HM}$ range is derived:

$$
n_{m}^{*}=\frac{z_{0} z_{2}}{z_{1} z_{5}} \frac{\left(k_{2}+1\right)\left(k_{1}+1\right)}{\left(k_{1}+k_{2}+1\right)\left(k_{3}+1\right)} n_{i},
$$

where $z_{0}, z_{1}, z_{2}$, and $z_{5}$ are tooth numbers of gears from input shaft to $K_{3}$, respectively; $k_{1}, k_{2}$, and $k_{3}$ are the characteristic parameters of three planetary gear sets.

(2) The engine speed deviation (absolute value) must be greater than the minimum setting value. In order to avoid repeating shift, the minimum engine speed deviation must be set. Only when the engine speed deviation is greater than it would the range shift be allowed.

(3) The condition of the driver's upshift must be satisfied. According to the traffic environment, the driver chooses a higher range through the range selector to limit vehicle speed. Only when the upshift is allowed by the range selector would the shift to a higher range be performed.

To sum up, the conditions of upshift from $\mathrm{H}$ range to $\mathrm{HM}$ range are

$$
\begin{aligned}
n_{m} & \geq n_{m}^{*} \\
n_{e}-n_{e}^{*} & \geq \Delta n_{e s e t} \\
S & =2 .
\end{aligned}
$$

The conditions of downshift from $\mathrm{HM}$ range to $\mathrm{H}$ range are

$$
\begin{gathered}
n_{m} \leq n_{m}^{*} \\
n_{e}-n_{e}^{*} \leq-\Delta n_{\text {eset }},
\end{gathered}
$$

where $S$ is the set value of the range selector. If $S=0$, HMT output speed is 0 ; if $S=1$, HMT can only run in $\mathrm{H}$ range; and when $S=2$, HMT can run in HM range. $\Delta n_{\text {eset }}$ is the minimum engine speed deviation.

\section{Range Shift Strategies}

In range shift process, the brake of current range is released, and the brake of target range is engaged. Brake switching sequence is determined by range shift logic, and range shift start time $t_{s}$ is determined by range shift conditions.

The motor rotational direction is constant during range shift. But the change of motor torque direction leads to the exchange of the high and low pressure circuits. Meanwhile, the power flow of hydraulic system reverses. The motor speed is fluctuated by the sudden change in pressure and volumetric efficiency of hydraulic unit. At the same time, the speed characteristics of HMT vary sharply, and the power characteristics change, which lead to noise and vibration.

It is range shift strategies that are responsible for the perfect engagement and disengagement of brakes to lower shift time and shock and to minimize input and output speed fluctuations [10]. Range shift strategies refer to control parameters and their control signals including variation, start time, and stop time. Range shift strategies in this work include the following:

(1) The overlap time between two brakes. $\Delta t_{s i}$ refers to the start time of oncoming brake to engage, and $\Delta t_{s s}$ refers to the start time of offgoing brake to release. The overlap time between brakes is

$$
\Delta t_{s}=\Delta t_{s i}-\Delta t_{s s}
$$

(2) Oil buffer during the offgoing brake release. It is affected by start time $\Delta t_{s b 1}$, end time $\Delta t_{s b 2}$, maximum pulse width $\gamma_{\text {smax }}$, and pulse width change of proportional relief valve signal.

(3) Displacement adjustment of the pump. It is determined by start time $\Delta t_{\text {sip } 1}$, end time $\Delta t_{\text {sip } 2}$, and displacement current variation $\Delta I_{s}$.

The above start time and end time are time increments relative to range shift start time $t_{s}$.

The timing and variation of the control variables of range shift strategies need to be determined by a number of simulations and experiments and are related to the following factors:

(1) The mechanical transmission scheme. Because of teeth matching in design of the mechanical transmission, the actual speed ratio of each range can not be equal to the ideal ratio of HMT, which is closely related to the displacement current variation $\Delta I_{s}$.

(2) Response characteristics and volumetric efficiency of the closed hydraulic circuit. The displacement current variation can only be accomplished in range shift and may cause an impact if its timing is incorrect. That is, the displacement current may vary after the offgoing brake is disengaged. Its start time $\Delta t_{\text {sip } 1}$ is greater than zero, and the end time $\Delta t_{\text {sip } 2}$ is related to response characteristics of the closed hydraulic circuit. The displacement current variation $\Delta I_{s}$ is affected by volumetric efficiency of the closed hydraulic circuit.

(3) Parameters of the brake. The overlap time $\Delta t_{s}$ is affected by the hydraulic cylinder diameter and stroke 


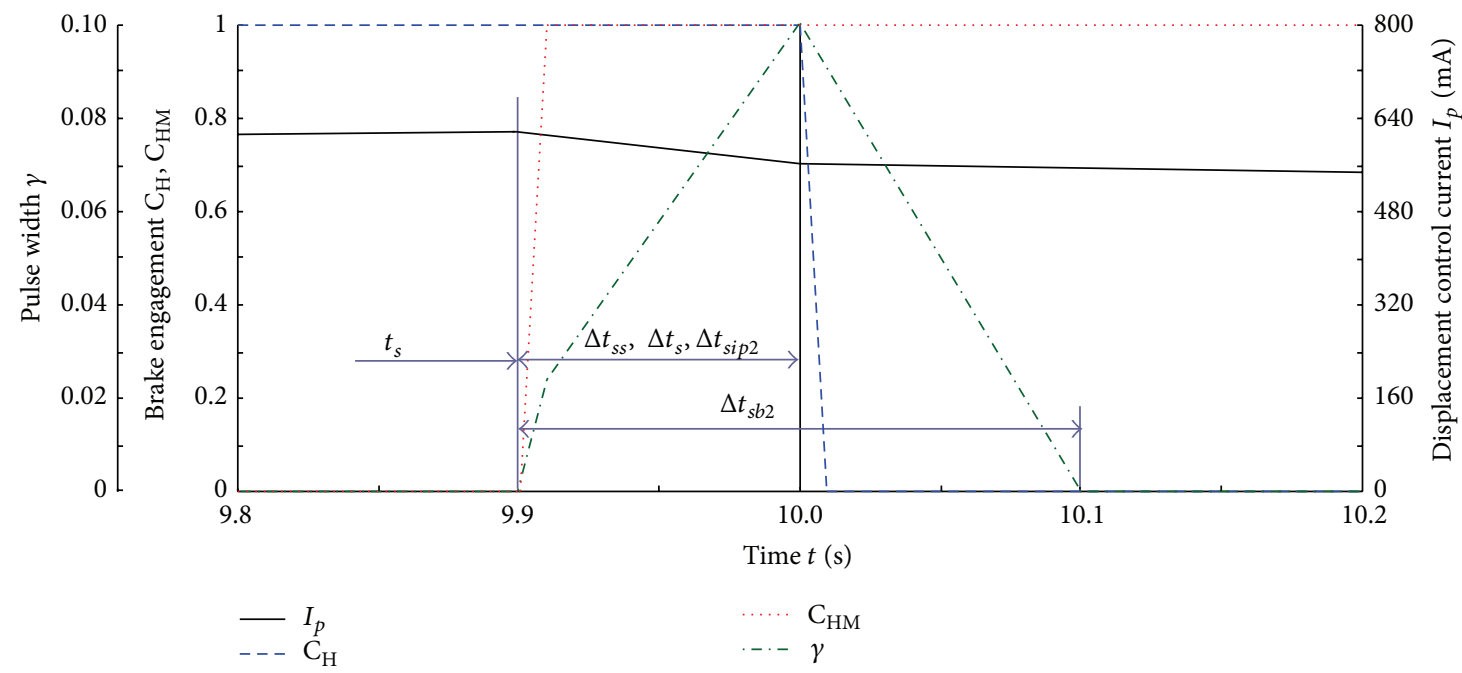

FIGURE 3: The range shift strategies from $\mathrm{H}$ range to HM range.

of the offgoing and oncoming brakes. Pulse width change process and the maximum pulse width $\gamma_{\text {smax }}$ of the proportional relief valve are influenced by the torque coefficient of the friction plate, stiffness, and initial displacement of the return spring in the offgoing brake. Diameter and length of the hydraulic circuit for controlling brake also have an effect on control signals.

Though the range shift strategies are different for different HMT schemes, there are several universal rules as follows:

(1) In upshift process from $\mathrm{H}$ range to $\mathrm{HM}$ range, the displacement current variation $\Delta I_{s}$ is negative, while in downshift process from $\mathrm{HM}$ range to $\mathrm{H}$ range, $\Delta I_{s}$ is positive.

(2) $\Delta t_{s i}, \Delta t_{s i p 1}$, and $\Delta t_{s s}$ are determined by lag time $t_{r r}$ of control mechanism for variable displacement hydraulic pump and oil-filled time $t_{c c}$ of the brake. If $t_{r r} \approx t_{c c}$, then $\Delta t_{s i}=\Delta t_{s i p 1}=0$. If $t_{r r}>t_{c c}$, then $\Delta t_{s i p 1}=0$ and $\Delta t_{s i}=t_{r r}-t_{c c}$. If $t_{r r}<t_{c c}$, then $\Delta t_{s i}=0$ and $\Delta t_{s i p 1}=t_{c c}-t_{r r} ; \Delta t_{s s}$ is slightly less than $t_{c c}$.

(3) The minimum oil pressure $p_{\gamma s \text { min }}$ of the oil pressure buffering needs to be greater than the minimum oil pressure to move piston of the brake.

According to the simulation results, the range shift strategies from $\mathrm{H}$ range to HM range are as follows: $\Delta t_{s i}=$ $\Delta t_{\text {sip1 }}=\Delta t_{s b 1}=0, \Delta t_{s s}=\Delta t_{\text {sip } 2}=\Delta t_{s}=0.1 \mathrm{~s}$, and $\Delta t_{s b 2}=0.2 \mathrm{~s} ; \Delta I_{s}=-14 \mathrm{~mA} ; \gamma_{s \max }=0.10$, as shown in Figure 3. The control signals from $\mathrm{HM}$ range to $\mathrm{H}$ range are the same as upshift in value and time, except for $\Delta I_{s}=14 \mathrm{~mA}$.

\section{Simulation of Control Strategies}

According to the control strategies, the model of controller is built in Matlab Simulink (Figure 4) and cosimulated with the model of a vehicle equipped with the two-range HMT.
The vehicle model is built in MSC Easy5 [16]. The results are shown in Figure 5.

When the coefficient of rolling resistance equals 0.02 , the throttle opening is shown in Figure 5(a). Control signals and speeds are shown in Figures 5(b), 5(c), and 5(d).

Before engine throttle is open (before $t=5 \mathrm{~s}$ ), the brake $\mathrm{C}_{\mathrm{H}}$ is engaged, and the other is disengaged. Engine is in idle state, HMT is in neutral range, and vehicle is parked. With the throttle opening $(t=5 \mathrm{~s})$, control signal $I_{P}$ begins to increase, HMT changes to $\mathrm{H}$ range, and the vehicle launches.

At the time of $t=11.2 \mathrm{~s}$, the HMT range shift conditions are satisfied from $\mathrm{H}$ range to $\mathrm{HM}$ range, and the controller begins to run range shift strategies (shown in Figure 3). During the range shift $(t=11.2 \mathrm{~s}-11.6 \mathrm{~s})$, the signal of brake $\mathrm{C}_{\mathrm{H}}$ decreases, and the signal of brake $\mathrm{C}_{\mathrm{HM}}$ increases gradually. The displacement current decreases by $14 \mathrm{~mA}$ $\left(\Delta I_{s}=-14 \mathrm{~mA}\right)$, and the rotational speed of engine fluctuates slightly. After the range shift, HMT comes into HM range. With the displacement of hydraulic pump decreasing, the vehicle accelerates in the HM negative half range. At the time of $t=21 \mathrm{~s}$, HMT passes the zero point into the HM positive half range, at which displacement is zero. In the HM positive half range, with displacement of hydraulic pump increasing reversely, the vehicle accelerates.

With the throttle decreasing and the target engine speed decreasing, the displacement current increases reversely until the actual engine speed is lower than its target speed. At the time of $t=27.5 \mathrm{~s}$, the vehicle speed starts to come down. At the time of $t=35 \mathrm{~s}$, engine throttle closes, the target engine speed steps, and the displacement current changes a lot. At the time of $t=40.5 \mathrm{~s}$, HMT falls back to the HM positive half range, and vehicle decelerates continuously. At the time of $t=44.2 \mathrm{~s}$, HMT comes into range shift from $\mathrm{HM}$ to $\mathrm{H}$ range, the control signal of brake $\mathrm{C}_{\mathrm{HM}}$ decreases gradually with the control signal of brake $\mathrm{C}_{\mathrm{H}}$ increasing. The displacement current increases by $14 \mathrm{~mA}\left(\Delta I_{s}=14 \mathrm{~mA}\right)$, the engine speed also fluctuates slightly, and HMT changes into 


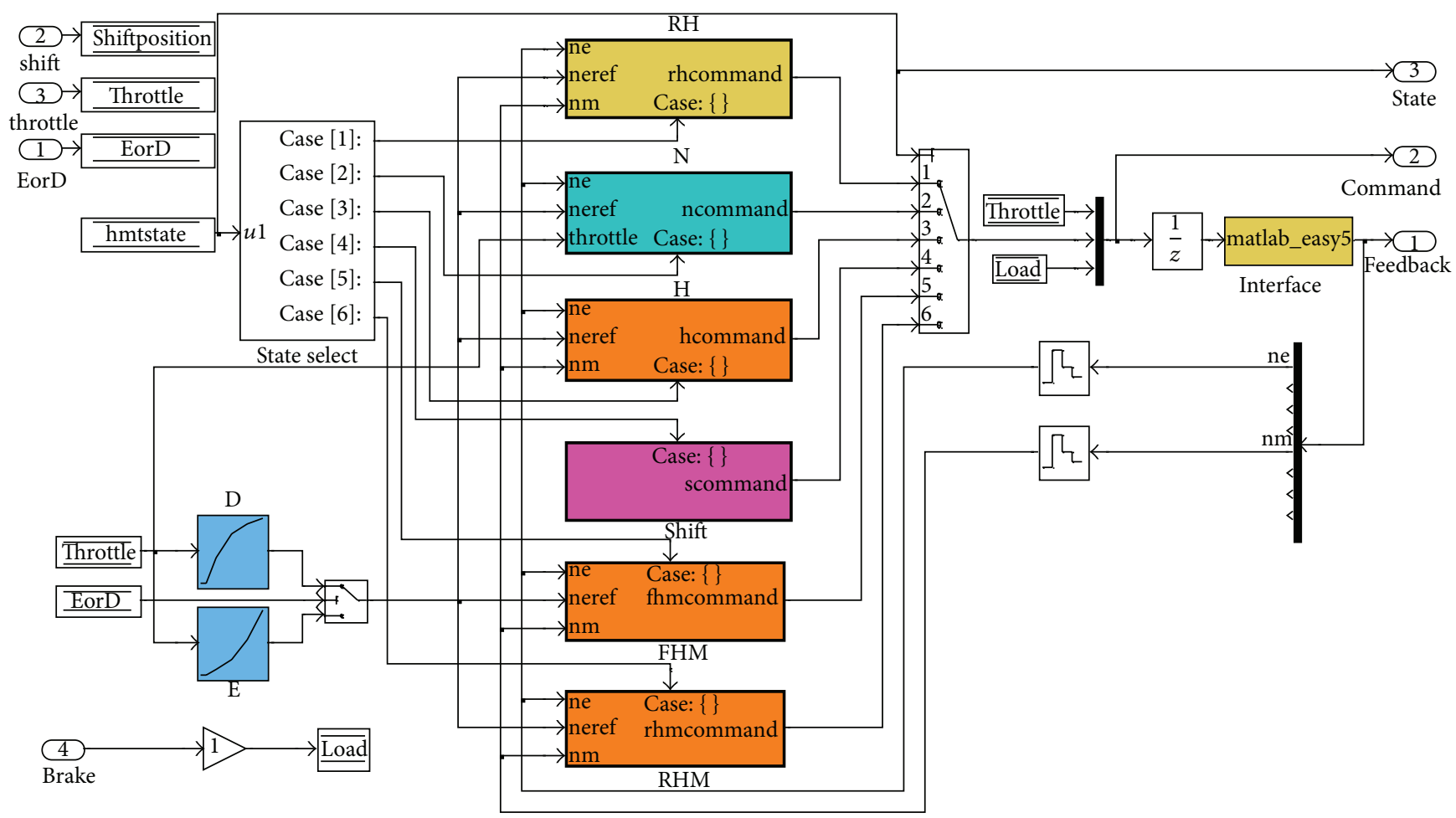

FIgURE 4: The controller model built in Matlab Simulink of the two-range HMT.

$\mathrm{H}$ range. At the time of $t=46 \mathrm{~s}$, HMT turns back to neutral range.

In Figure 5, the control current of hydraulic pump does not fluctuate in range. There is no repeating shift. Engine drops to the idle speed after HMT turns back to neutral range.

The ideal and actual speeds of engine are shown in Figure 5(c). The launch of vehicle takes $1.2 \mathrm{~s}$ (from $5 \mathrm{~s}$ to $6.2 \mathrm{~s}$ ). After vehicle launches, $n_{e}$ is obviously larger than $n_{e}^{*}$. From $t=6.2 \mathrm{~s}$, as the engine load is heavier, $n_{e}$ drops fast to a little higher than $n_{e}^{*}$. After that, $n_{e}$ keeps close to $n_{e}^{*}$, and the maximum difference is $44 \mathrm{r} / \mathrm{min}$ (except for the zero points of hydraulic pump and range shifts). $n_{e}$ drops to less than $n_{e}^{*}$, after the throttle closes. $n_{e}$ quickly declines down to $n_{e}^{*}$. Because of the vehicle inertia, the actual engine speed remains for some time (about 10.1s), with the adjustment of HMT. When the vehicle speed approximately equals zero, the engine drops fast to idle speed.

The vehicle speed $u_{a}$ is shown in Figure 5(d). With vehicle launching, accelerating, decelerating, and stopping, speed fluctuation does not happen, during range shifts or at the zero points.

\section{Hardware in the Loop Simulation}

The HILS of HMT is a test method, on the basis of the computer simulation system. In the HILS test, the HMT object replaces the HMT model in the simulation circuit. And it is directly controlled by the controller through input/output devices and interface circuit.

Due to the HMT object connected to the simulation circuit, this test can further prove the reliability of simulation results. This method can check the correctness of control strategy on the basis of HMT computer simulation and adjust control parameters accurately. It can also check the correctness of HMT simulation model. It is especially effective for using a gray box model to describe the HMT which is difficult to describe by a mathematical model.

Based on $330 \mathrm{~kW}$ dynamic simulation test bench, the original load objects drive and load the HMT according to the engine and vehicle dynamic characteristics through the realtime model driving. In this system, the HMT is a material object, and the other parts are all models or are driven by models. The HILS system is shown in Figure 6. And some objects of the HILS test are shown in Figure 7.

The HILS software of HMT is made up of the HMT controller model, the engine model, vehicle real-time models, and real-time windows target. Under the control of the engine real-time model, load component 2 of the dynamic simulation test bench which runs according to the engine characteristics provides power for the HMT. Under the control of the vehicle real-time model, load component 1 loads the HMT according to the vehicle traffic characteristics. The controller model does real-time control of HMT according to the control strategies. The HMT adjusts speed ratio according to the change of vehicle working conditions, which makes the engine run at the approximately optimal speed (the best fuel economy or the best performance).

The input of engine real-time model is the load torque $T_{q}$, and the output is the engine speed $n_{e}$. On the dynamic simulation test bench, the load component 2 simulating engine is under the control of constant speed mode. Speed and torque detector 2 feeds load torque back to a simulation 

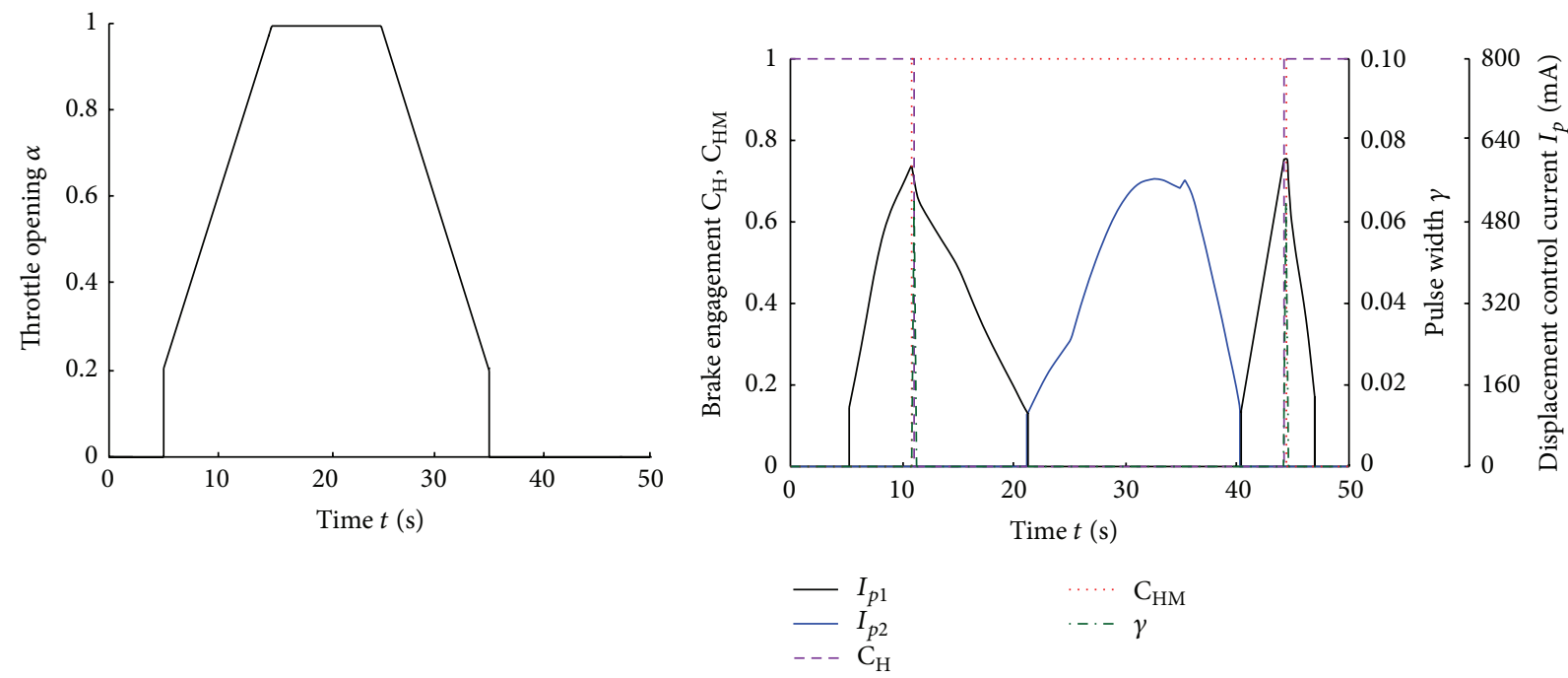

(a)

(b)
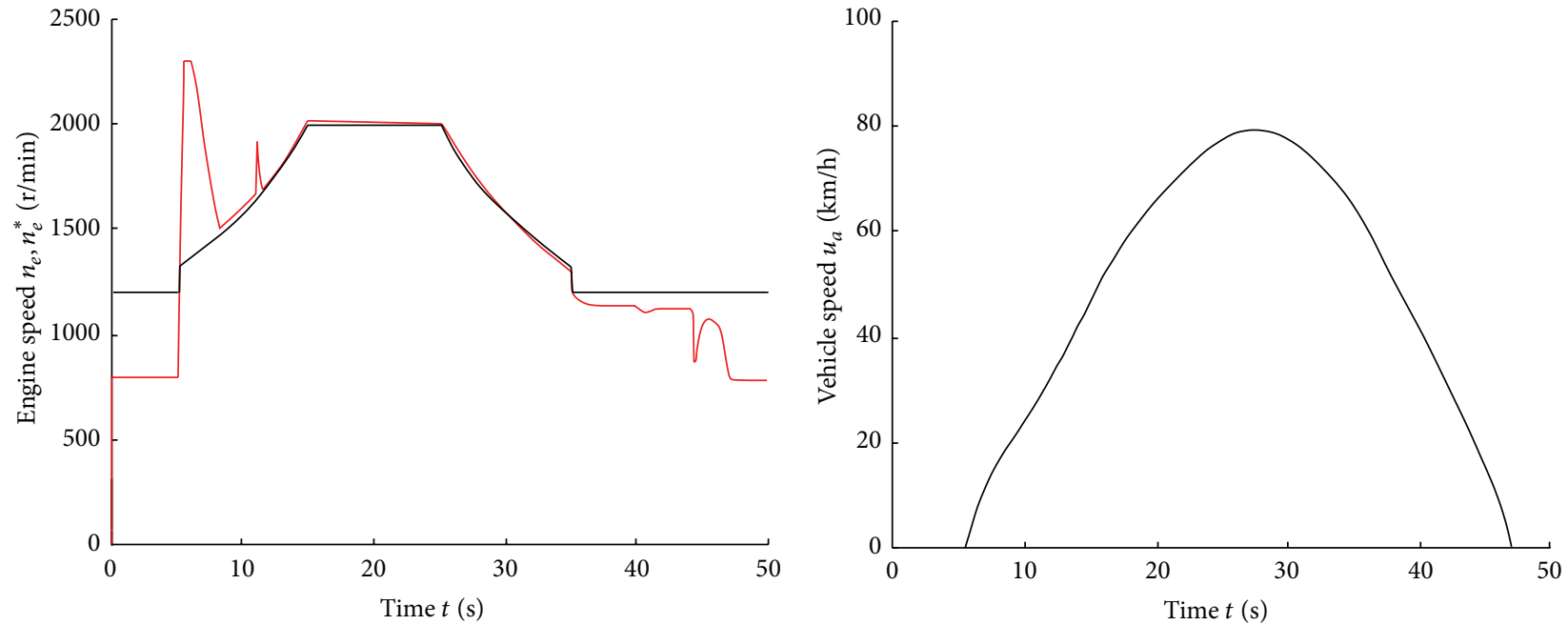

- Actual engine speed $n_{e}$

— Ideal engine speed $n_{e}^{*}$

(c)

(d)

Figure 5: Dynamic response of vehicle.

computer. The calculation result of the engine real-time model is given to load component 2 .

The engine real-time model can be described as

$$
\begin{aligned}
& J_{e} \dot{\omega}_{e}=T_{e}\left(\alpha, n_{e}\right)-T_{q} \\
& \text { So }\left\{\begin{array}{l}
\dot{\omega}_{e}=\frac{T_{e}\left(\alpha, n_{e}\right)-T_{q}}{J_{e}} \\
n_{e}=\frac{60}{2 \pi} \int \dot{\omega}_{e} \\
V_{e}=\frac{n_{e}}{A_{\omega}},
\end{array}\right.
\end{aligned}
$$

where $J_{e}$ is the simulated engine's inertia, $T_{e}\left(\alpha, n_{e}\right)$ is the static output torque of simulated engine, $T_{q}$ is the load torque by feedback of speed torque sensor, $n_{e}$ is the output speed of the load component $2, V_{e}$ is the control voltage of the load component 2 controller, and $A_{w}$ is the control voltage linear conversion coefficient of the load component 2 .

In the computer simulation model, the input and output of vehicle model are the output speed and load torque of HMT, respectively. On the dynamic simulation test bench, load component 1 simulating vehicle is under the control of constant torque mode. To ensure that input and output are consistent with calculation in the simulation model, "virtual axis" needs to be introduced to the vehicle real-time model. 


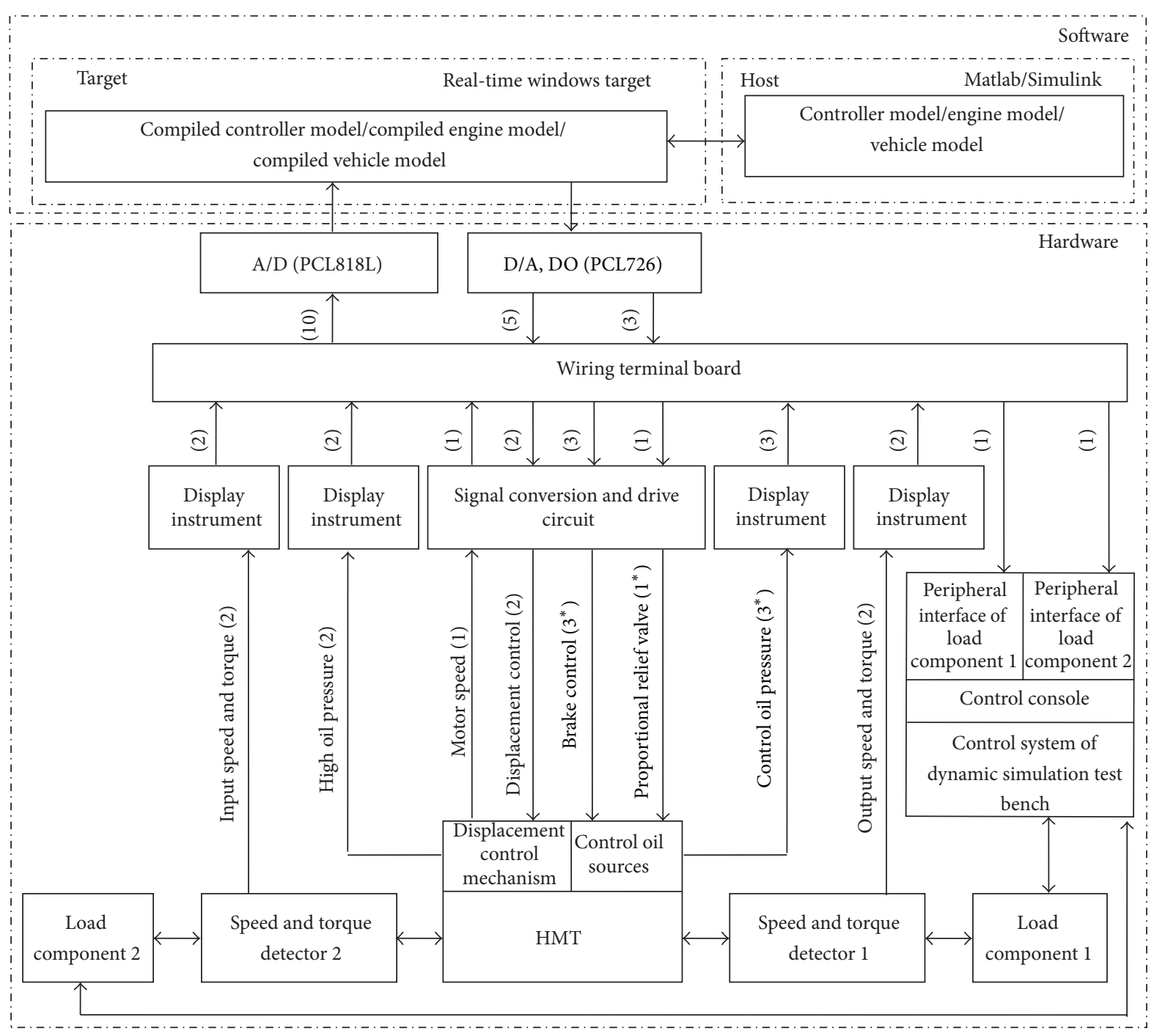

Figure 6: The HILS system of HMT.

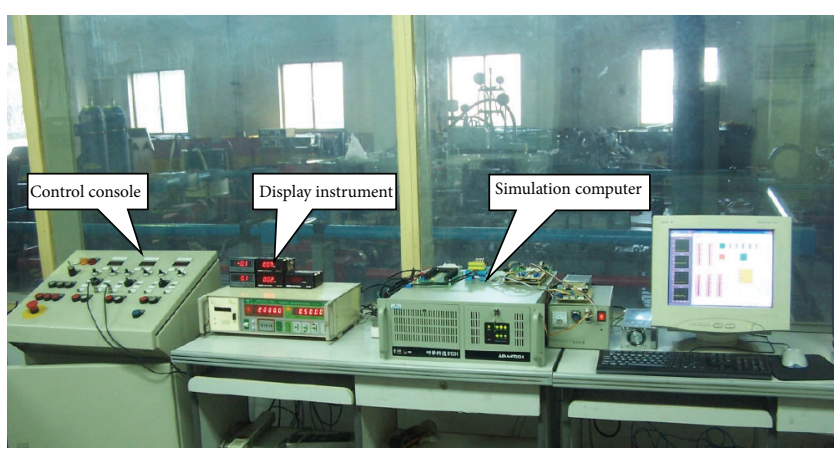

(a)

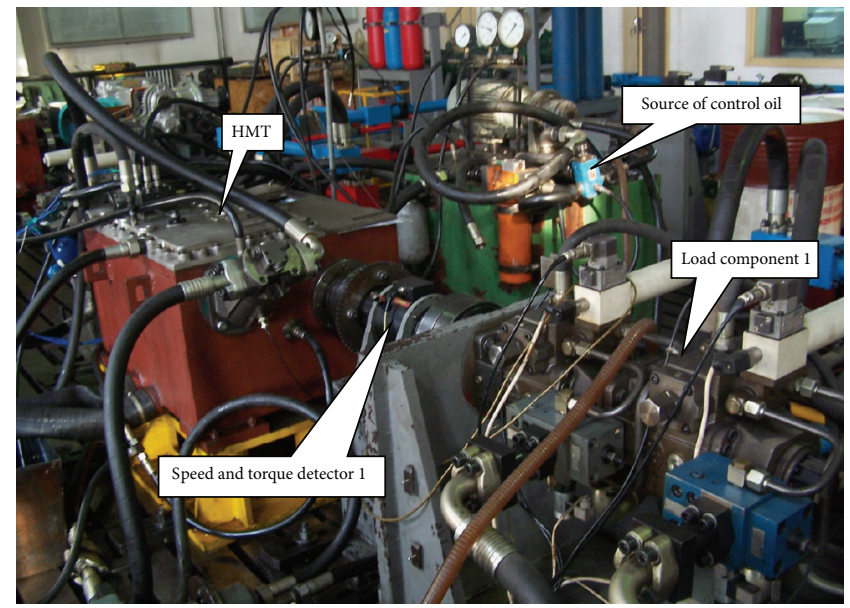

(b)

Figure 7: Some objects of the HILS test. 


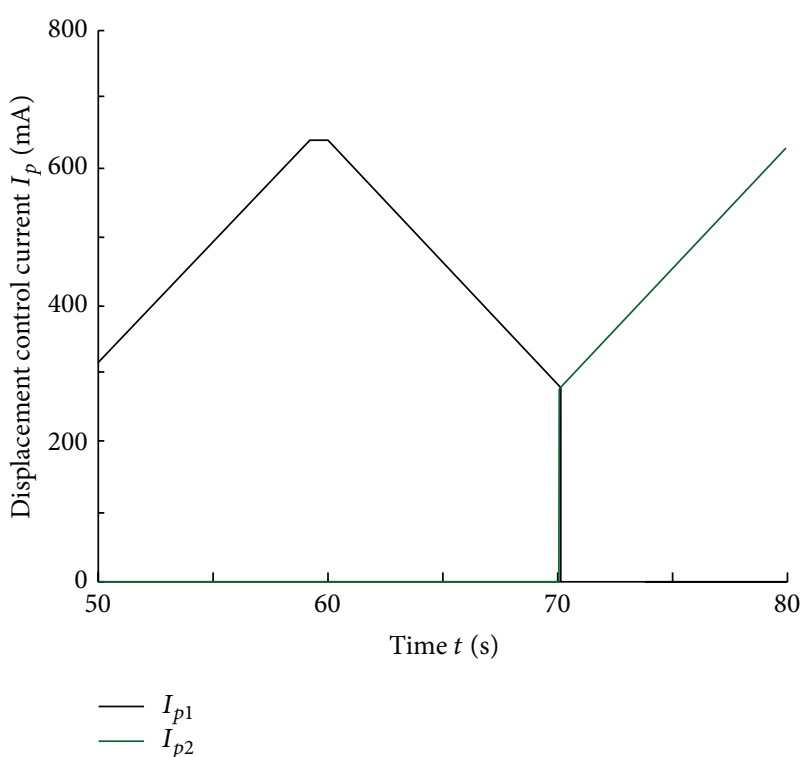

(a)

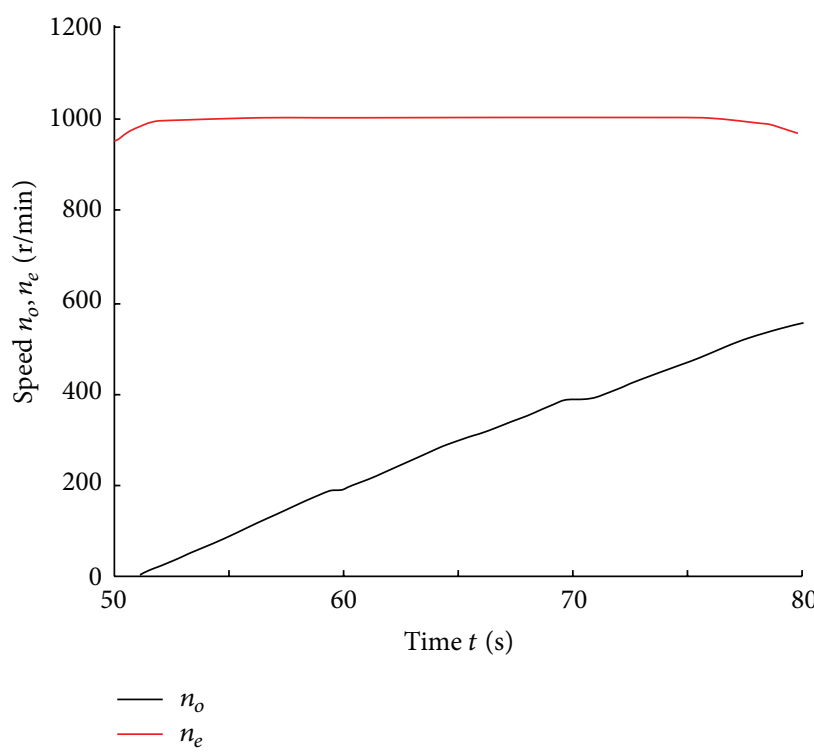

(c)

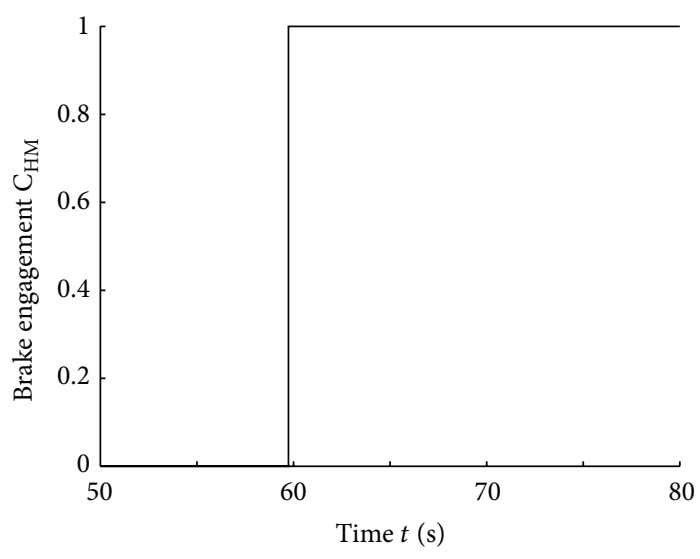

(b)

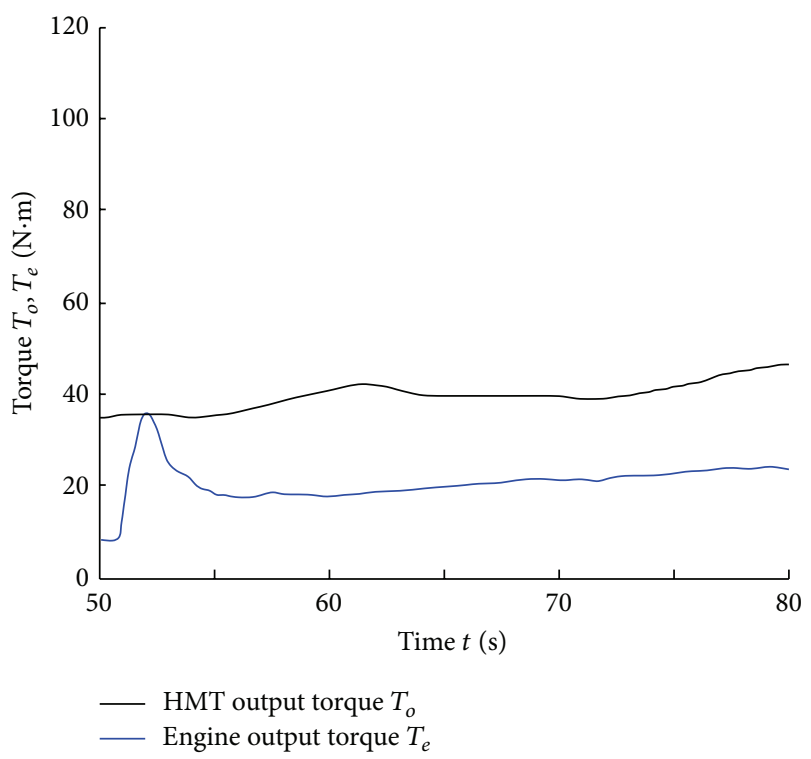

(d)

FIgURE 8: The test results of the HMT range shift process.

The output torque of the vehicle real-time model is

$$
\begin{aligned}
T_{d 1} & =\int k\left(\omega-\omega_{1}\right) d t+c\left(\omega-\omega_{1}\right) \\
\dot{\omega}_{1} & =\frac{T_{d 1}-\left(F_{f}+F_{W}+F_{i}+F_{b}\right) r / i_{0}}{m\left(r^{2} / i_{0}^{2}\right)-J_{d 1}} \\
V_{T} & =\frac{T_{d 1}}{A_{T}},
\end{aligned}
$$

where $k$ is the torsional stiffness of virtual axis, $c$ is the damping of virtual axis, $T_{d 1}$ is the output torque of the vehicle real-time model, $\omega$ is the feedback speed signal of the speed sensor, $\omega_{1}$ is the angular speed of vehicle equivalent inertia, $V_{T}$ is the control voltage of the load component 1 controller, and $A_{T}$ is the control voltage linear conversion coefficient of the load component 1 .

Under load component 1 working without load by manual control mode, the HMT range shift test results are shown in Figure 8. The figures show that the range shift process is smooth and speed fluctuation does not happen. It demonstrates that the control strategy of range shift determined by the motor speed is reasonable. When the load increases, the output speed fluctuates clearly in range shift process. It states that the range shift control strategies are necessary. 

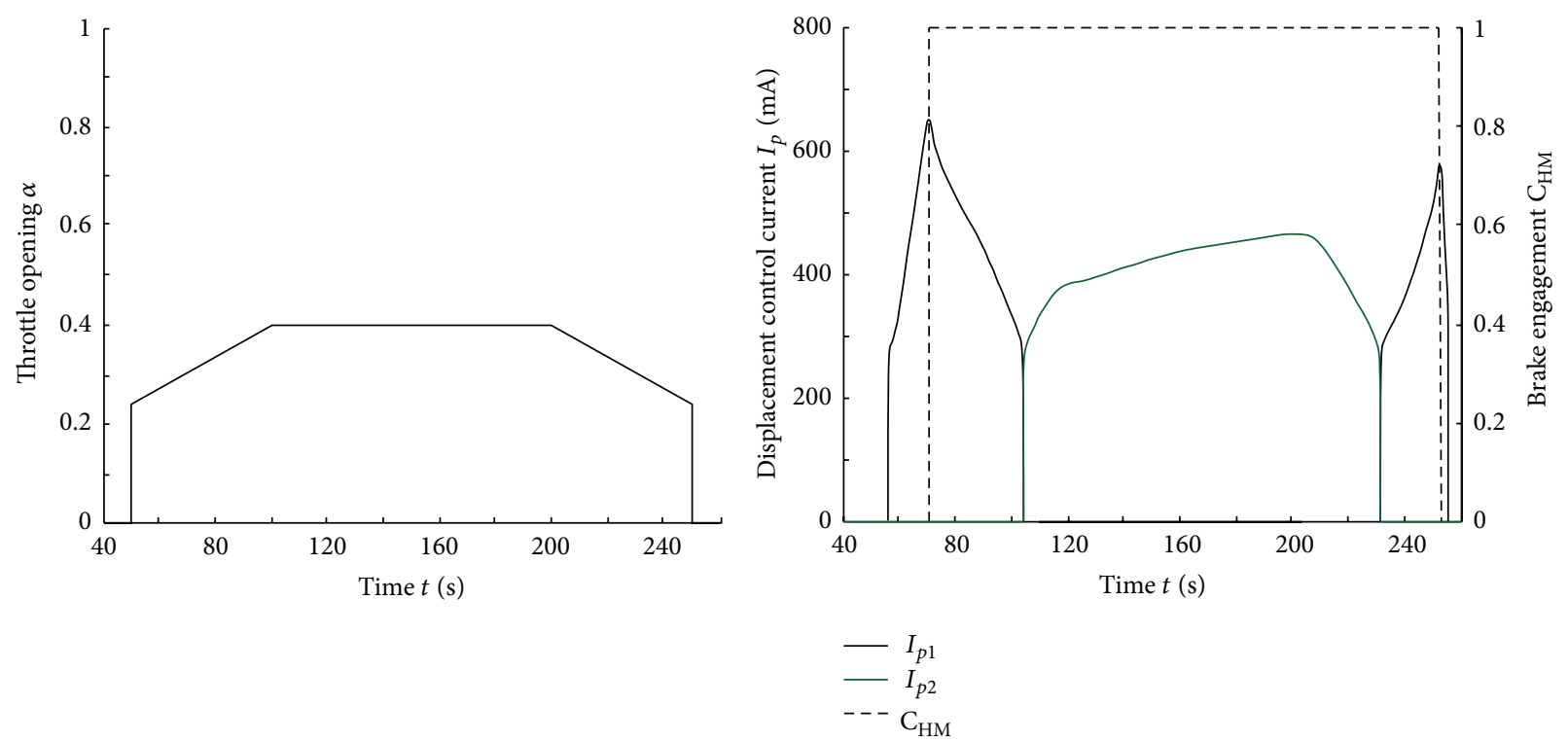

(a)

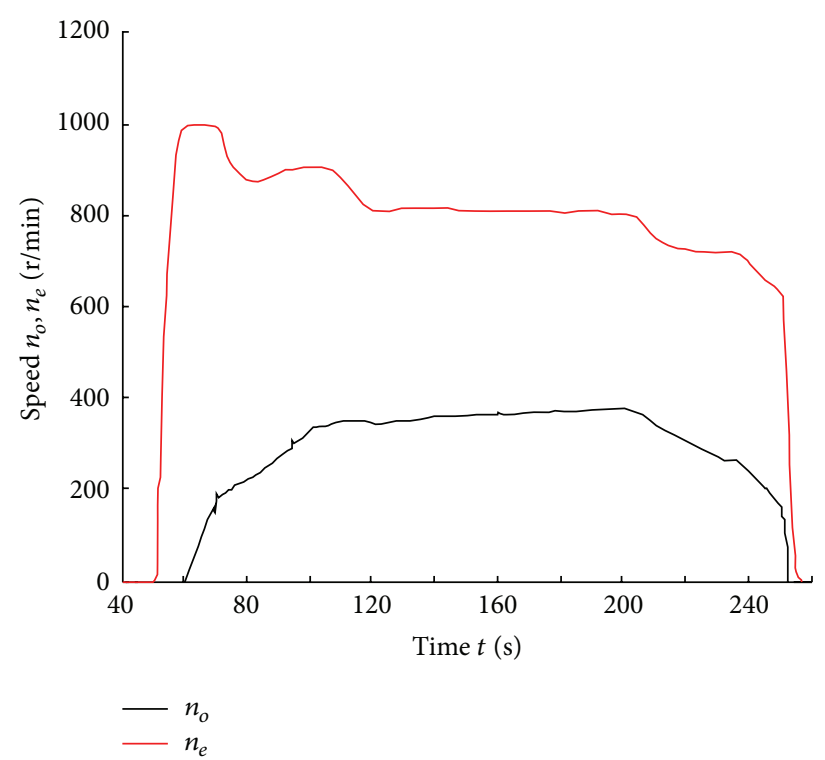

(c) (b)

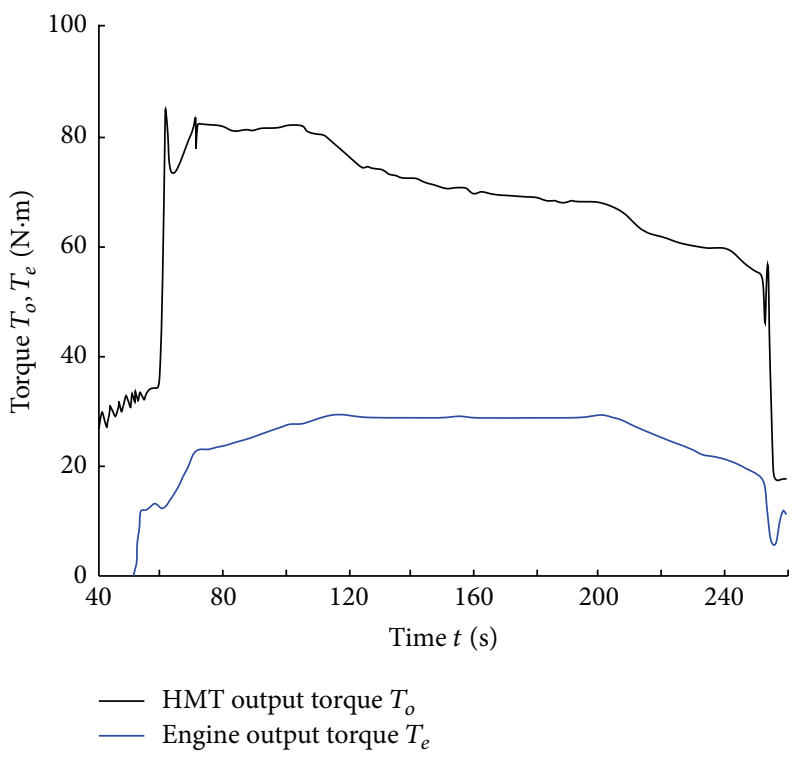

(d)

FIgURE 9: The vehicle dynamic characteristics.

When load components 1 and 2 are automatically controlled, the curve of the engine throttle is shown in Figure 9(a), and the HMT responses are shown in Figure 9 (b). The main performance indicators are shown in Figures 9(c) and 9(d). From Figure 9, with engine throttle changing, the HMT speed ratio changes under the control of the controller model. In the throttle stable stage, the engine speed is adjusted to the near optimal speed, and its change rules are in accordance with simulation results. Because of the adjustment of engine performance and vehicle inertia, the engine can work at its top speed for a long time.

\section{Conclusions}

(1) The integrated control strategy of HMT is proposed. The algorithm of the asymmetric saturated incremental PID speed control strategy in range and range shift conditions are derived. And this paper presents the range shift logic and range shift control strategies.

(2) A controller model is built in Matlab Simulink and cosimulated with the model of vehicle equipped with a two-range HMT. Simulation results indicate that under the control of the proposed strategies the 
engine runs near ideal speed, and the vehicle meets driving requirements with the throttle changing.

(3) The HILS test of HMT is carried out. The test results show that the range shift process is smooth and speed fluctuation does not happen. In the throttle stable stage, the engine speed is adjusted to the near optimal speed, and its change rules are in accordance with simulation results.

(4) The results demonstrate that the HMT model is correct, and the control strategy is reasonable. The system of HILS works reliably and meets the requirements of the HMT dynamic characteristics study.

\section{Conflict of Interests}

The authors declare that there is no conflict of interests regarding the publication of this paper.

\section{Acknowledgments}

This work is supported by the National Natural Science Foundation of China (Grant no. 51175449) and the Scientific Research Program of Higher Education of Hebei Province (Grant no. Z2015081).

\section{References}

[1] M. Kulkarni, T. Shim, and Y. Zhang, "Shift dynamics and control of dual-clutch transmissions," Mechanism and Machine Theory, vol. 42, no. 2, pp. 168-182, 2007.

[2] P. D. Walker, N. Zhang, and R. Tamba, "Control of gear shifts in dual clutch transmission powertrains," Mechanical Systems and Signal Processing, vol. 25, no. 6, pp. 1923-1936, 2011.

[3] H. Aitzetmüller, "Steyr S-Matic-the future CVT system," in Proceedings of the FISITA World Automotive Congress, Seoul, Republic of Korea, June 2000.

[4] R. P. Northup, Development and Test of HMPT-500, Ordnance Systems Department, General Electric, Pittsfield, Mass, USA, 1974.

[5] P. Linares, V. Méndez, and H. Catalán, "Design parameters for continuously variable power-split transmissions using planetaries with 3 active shafts," Journal of Terramechanics, vol. 47, no. 5, pp. 323-335, 2010.

[6] R. Kumar, M. Ivantysynova, and K. Williams, "Study of energetic characteristics in power split drives for on highway trucks and wheel loaders," SAE Technical Papers 2007-01-4193, 2007.

[7] A. Macor and A. Rossetti, "Optimization of hydro-mechanical power split transmissions," Mechanism and Machine Theory, vol. 46, no. 12, pp. 1901-1919, 2011.

[8] M. Zhang and Z. Zhou, "Modeling and control simulation for the multi-range hydro-mechanical CVT," Key Engineering Materials, vol. 621, pp. 462-469, 2014.

[9] S. H. Choi, H. J. Kim, S. H. Ahn et al., "Modeling and simulation for a tractor equipped with hydro-mechanical transmission," Journal of Biosystems Engineering, vol. 38, no. 3, pp. 171-179, 2013.

[10] S. Yuan, G. Hou, and B. Zhang, "Variable parameter PID control for hydro-mechanical continuously variable transmission," Chinese Journal of Mechanical Engineering, vol. 40, no. 7, pp. 81-84, 2004.
[11] C. Wei, S. Yuan, J. Hu, and W. Song, "Theoretical and experimental investigation of speed ratio follow-up control system on geometric type hydro-mechanical transmission," Journal of Mechanical Engineering, vol. 47, no. 16, pp. 101-105, 2011.

[12] J. Hu, C. Wei, S. Yuan, and C. Jing, "Characteristics on hydro-mechanical transmission in power shift process," Chinese Journal of Mechanical Engineering, vol. 22, no. 1, pp. 50-56, 2009.

[13] M. Zhang and Z. Zhou, "Speed change and range shift control schedule of the multi-range hydro-mechanical CVT for farm tractors," in Proceedings of the IEEE International Conference on Mechatronics and Automation (ICMA '06), vol. 2006, pp. 19701974, June 2006.

[14] S. M. Savaresi, F. L. Taroni, F. Previdi, and S. Bittanti, "Control system design on a power-split CVT for high-power agricultural tractors," IEEE/ASME Transactions on Mechatronics, vol. 9, no. 3, pp. 569-579, 2004.

[15] M. Tanelli, G. Panzani, S. M. Savaresi, and C. Pirola, "Transmission control for power-shift agricultural tractors: design and end-of-line automatic tuning," Mechatronics, vol. 21, no. 1, pp. 285-297, 2011.

[16] S. Yang, H. Xia, Z. Han, and H. Pan, "Controller hardware-inloop simulation of hydraulic mechanical transmission based on sync signal," Transactions of the Chinese Society of Agricultural Engineering, vol. 28, no. 4, pp. 33-38, 2012. 


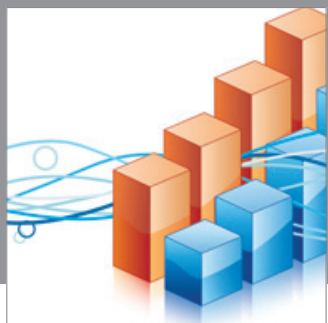

Advances in

Operations Research

mansans

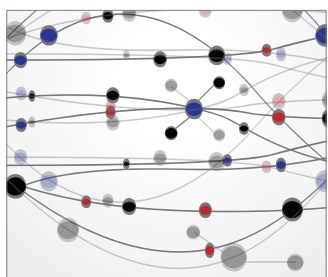

The Scientific World Journal
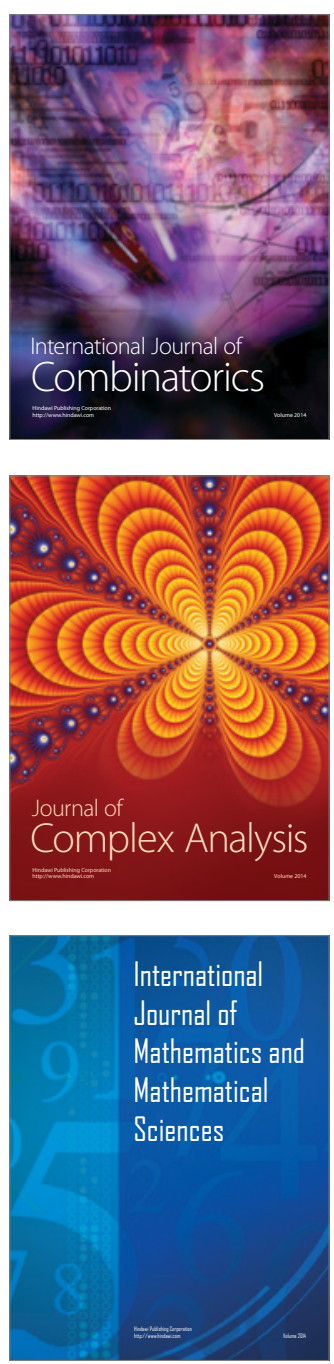
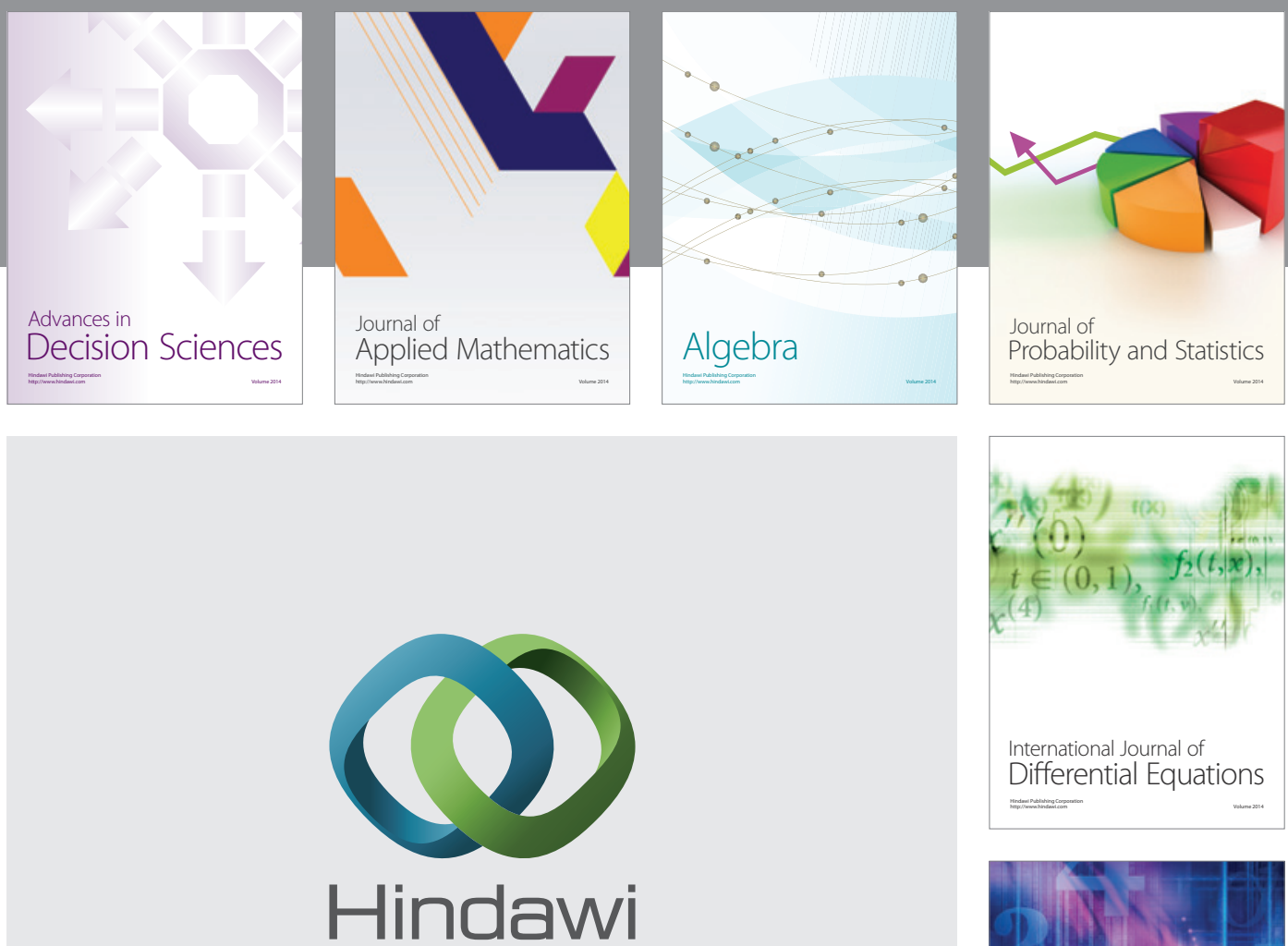

Submit your manuscripts at http://www.hindawi.com
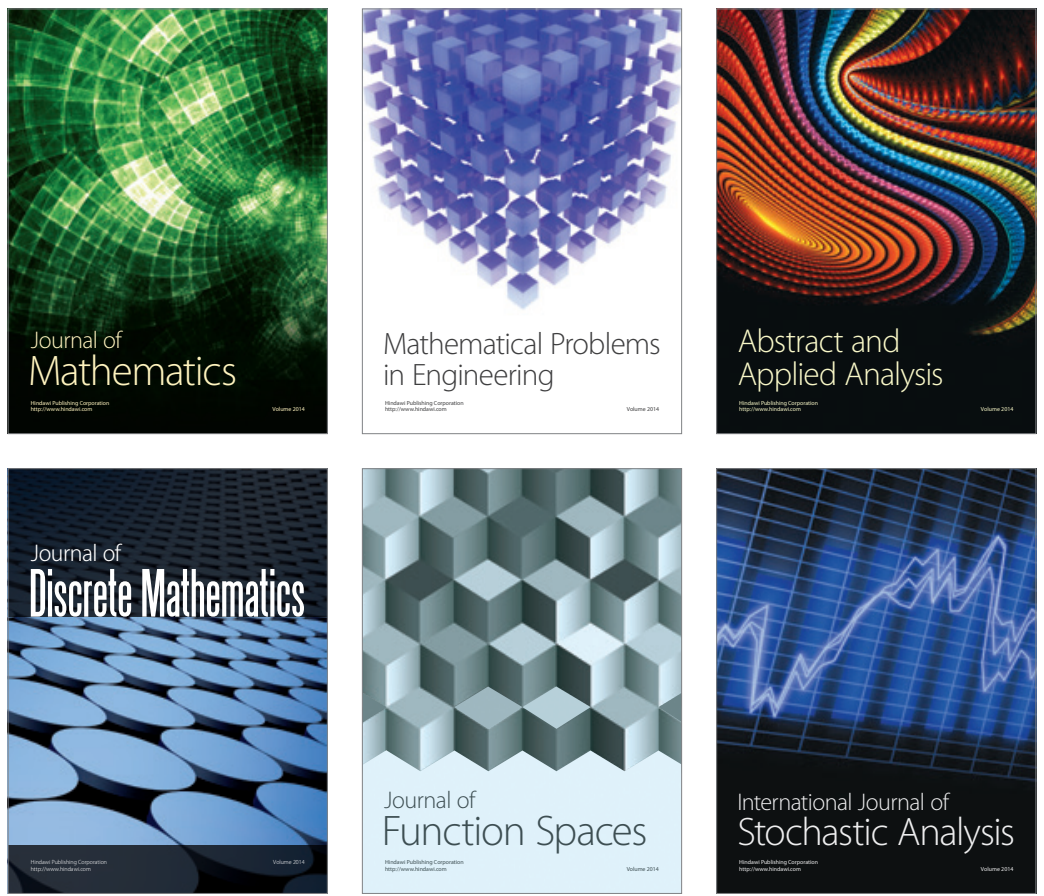

Journal of

Function Spaces

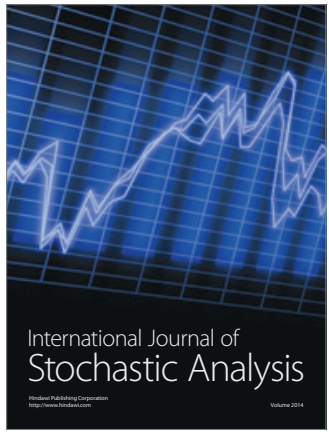

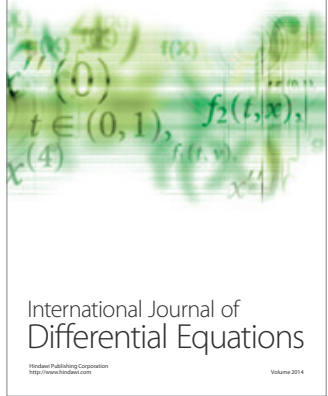
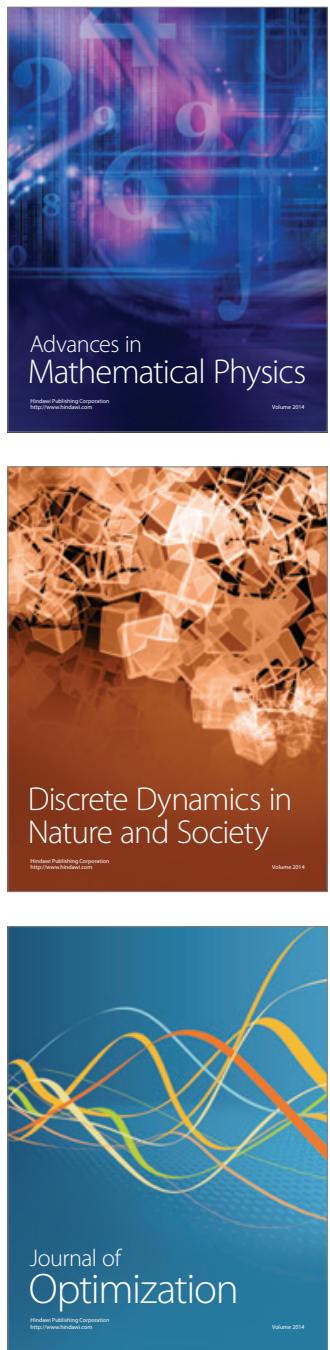